\title{
Audiology
}

\section{Benefits of active middle ear implants over hearing aids in patients with sloping high tone hearing loss: comparison with hearing aids}

\author{
Benefici degli impianti attivi dell'orecchio medio rispetto alle protesi acustiche \\ tradizionali nei pazienti con perdita dell'udito per le frequenze acute

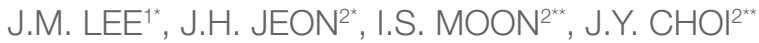 \\ ${ }^{1}$ Department of Otorhinolaryngology, Ilsan Paik Hospital, Inje University College of Medicine, Goyang, Korea; \\ 2 Department of Otorhinolaryngology, Yonsei University College of Medicine, Seoul, Korea \\ * These authors contributed equally to this work \\ ** Equal contributions as corresponding author
}

\section{SUMMARY}

In this retrospective chart review we compared the subjective and objective benefits of active middle ear implants (AMEIs) with conventional hearing aids (HAs) in patients with sloping high tone hearing loss. Thirty-four patients with sensorineural hearing loss were treated with AMEIs. Of these, six had sloping high tone hearing loss and had worn an HA for more than 6 months. Objective assessments, a pure-tone audiogram, as well as a word recognition test, and the Korean version of the Hearing in Noise Test (K-HINT), and a subjective assessment, the Abbreviated Profile of Hearing Aid Benefit (APHAB) questionnaire, were performed. Tests were conducted under three circumstances: 1) the unaided state before surgery; 2) the HA-aided state before surgery; and 3) the AMEI-aided state 3 months after surgery. The average high-frequency hearing gain $(\geq 2 \mathrm{kHz})$ was significantly better with AMEIs than with HAs. Although the result had no statistical significance, AMEIs showed a superior word recognition score (WRS) compared to HAs. However, the most comfortable hearing level at which the WRS was tested was significantly decreased with an AMEI compared to an HA. In the K-HINT, patients with an AMEI showed greater recognition than those fitted with an HA under both quiet and noisy conditions. The APAHB scores revealed that patients were more satisfied with an AMEI rather than an HA on all subscales. The use of vibroplasty in patients with sloping high tone loss resulted in positive hearing outcomes when compared to conventional HAs. Based on the data from this study, AMEIs provided better objective and subjective results and could, therefore, be a better alternative for the treatment of sloping hearing loss.

KEY WORDS: Middle ear implant $\bullet$ Hearing loss $\bullet$ High frequency $\bullet$ Hearing impaired rehabilitation $\bullet$ Hearing aids

\begin{abstract}
RIASSUNTO
In questo studio retrospettivo, abbiamo confrontato i benefici oggettivi e soggettivi degli impianti attivi dell'orecchio medio (AMEI) rispetto alle tradizionali protesi acustiche (HA) nei pazienti con perdita dell'udito per le frequenze acute. Trentaquattro pazienti con ipoacusia neurosensoriale sono stati trattati con l'impianto di AMEI. Tra questi, sei avevano un audiogramma "in discesa" con perdita dell'udito per le frequenze acute, ed avevano usato per più di sei mesi HA. È stata quindi eseguita una valutazione oggettiva, tramite l'audiometria tonale e il test di riconoscimento delle parole, una versione coreana del "Hearing in Noise Test" (K-HINT), ed una valutazione soggettiva tramite il seguente questionario: Abbreviated Profile of Hearing Aid Benefit (APHAB). I pazienti sono stati sottoposti ai suddetti test in tre occasioni distinte: 1) prima della chirurgia, senza protesi; 2) prima della chirurgia, con HA; 3) tre mesi dopo l'impianto di AMEI. Il guadagno medio per le alte frequenze ( $\geq 2 \mathrm{kHz}$ ) si è rivelato migliore con AMEI che con HA. Sebbene il risultato non ha raggiunto un livello di significatività statistica, gli impianti attivi dell'orecchio medio hanno mostrato un punteggio di riconoscimento delle parole superiore rispetto a HA. Ad ogni modo, il livello di comoda udibilità al quale il punteggio di riconoscimento delle parole è stato testato si è rivelato significativamente più basso con AMEI rispetto ad HA. Al K-HINT i pazienti con AMEI hanno mostrato un migliore riconoscimento rispetto ai risultati ottenuti con HA, sia in condizione di quiete sia di rumore. Gli score APAHB hanno rivelato che i pazienti erano più soddisfatti con AMEI. L'uso degli impianti attivi dell'orecchio medio in pazienti con perdita dell'udito per le frequenze acute ha permesso di ottenere risultati migliori rispetto all'utilizzo delle protesi tradizionali. Basandoci su questi dati, gli AMEI hanno offerto risultati oggettivi e soggettivi migliori, e pertanto, potrebbero rappresentare una valida alternativa per il trattamento delle ipoacusie con audiogramma in discesa.
\end{abstract}

PAROLE CHIAVE: Impianti dell'orecchio medio $\bullet$ Ipoacusia per le frequenze acute $\bullet$ Riabilitazione uditiva $\bullet$ Protesi acustiche 


\section{Introduction}

Sloping high tone hearing loss is defined as relatively intact hearing at frequencies lower than $500 \mathrm{~Hz}$ and decreased hearing at frequencies greater than $3 \mathrm{kHz}$, with thresholds exceeding the low frequencies by more than $30 \mathrm{~dB}^{1}$. Sloping high tone loss occurs in up to $31 \%$ of patients with hearing loss ${ }^{2}$. Patients with this condition can recognise small sounds, but their speech discrimination ability decreases and they often have difficulty communicating in against a background of daily noise. Most individuals with mild-to-moderate sensorineural hearing loss would benefit from using conventional hearing aids (HAs), but patients with sloping high tone loss do not gain any particular benefit from conventional HAs. It is reported that less than 4 in 10 people use an HA secondary to complaints of occlusion, ear canal discomfort, distortion, feedback, difficulty with background noise, and limited benefit at high frequencies ${ }^{3}$.

Open-fitting HAs have recently been developed to overcome these limitations. This type of HA has an open ear mould and the microphone is separate from the receiver, thereby reducing the effects of occlusion and acoustic feedback to some extent. However, because the amplification peak in open-fitting HAs decreases dramatically above $4 \mathrm{kHz}$, their use in patients with sloping high tone hearing loss remains limited ${ }^{4}$. For this particular population, who fall outside traditional cochlear implant candidacy guidelines and who continue to struggle with HAs, hybrid cochlear implantation has emerged as a potential solution. Its design incorporates a short cochlear implant electrode that is used to electrically stimulate basally located high frequencies, while preserving apically-located low frequencies for acoustic stimulation. Several studies have demonstrated the benefits of this type of implant for speech recognition under both quiet and noisy conditions, as well as for music perception in patients ${ }^{56}$. However, hybrid cochlear implantation is not without risk. Patients may lose their residual hearing at low frequencies as a result of surgery, and residual hearing loss following implantation may occur with a shorter electrode that has a reduced capacity to stimulate the apically located low frequencies; therefore, there is always the potential to undergo re-implantation with a standard length electrode design.

Because of these limitations, the role of active middle ear implants (AMEIs) in the treatment of moderate-tosevere sloping high tone loss continues to be explored as an alternative to HAs. The Vibrant Soundbridge ${ }^{\circledR}$ (VSB; Med-El, Innsbruck, Austria) was developed for patients with moderate-to-severe hearing loss and functions by coupling the floating mass transducer (FMT) to the long process of the incus. The VSB comprises an externally worn speech processor and an implanted signal processor (vibrating ossicular replacement prosthesis) with an
FMT. Vibroplasty does not occlude the external auditory canal and transmits sound energy to ossicles through direct-drive stimulation; thus, it is not associated with wearing problems and provides adequate and stable functional gain.

Many studies have reported greater hearing performance and satisfaction with vibroplasty than with an HA, as vibroplasty solves the problem of wearing the device in the canal ${ }^{4-12}$. The aim of the current study was to evaluate the effect of vibroplasty in patients with sloping high tone hearing loss using both objective and subjective assessments.

\section{Materials and methods}

\section{Patients}

A total of 34 subjects underwent vibroplasty between October 2011 and October 2013 at our tertiary hospital. Of these, six patients had sloping high tone hearing loss and were included in the study. These patients completed audiological tests and self-assessment questionnaires. Sloping high tone hearing loss was defined as a difference of $30 \mathrm{~dB}$ or more between the pure-tone thresholds at 250$500 \mathrm{~Hz}$ and $3 \mathrm{kHz}$ in the implanted ear. All patients had worn an HA for more than 6 months before AMEI implantation. The VSB was used for all implanted devices along with the Amade $^{\circledR}$ (Med-EL, Innsbruck, Austria) speech processor. The VSB was switched on at 8 weeks after surgery, and postoperative evaluation was performed after 3 months.

The study was approved by the Institutional Review Board of the Severance Hospital in Seoul, Korea (42012-0474).

\section{Surgical procedure}

None of the study patients had undergone previous ear surgery. A mastoidectomy and posterior tympanotomy were simultaneously performed. The posterior tympanotomy was performed widely so that the long process of the incus was clearly visible, and was extended anteriorly and superiorly so that the FMT could be safely introduced. The attachment clip of the FMT was firmly attached to the long process of the incus using clippers. An implant bed was drilled into the occipitotemporal bone to fix the implant housing with bone-anchored sutures. Procedures were performed under general anaesthesia in all patients.

\section{Objective assessment}

The six selected patients completed a pure-tone audiogram (PTA), word recognition test (the word recognition score; WRS), and the Korean version of the Hearing in Noise Test (K-HINT), both pre- and postoperatively. The PTA was conducted at frequencies of 250-8,000 Hz. The average hearing threshold was defined as the mean of the 
following frequencies: $500 \mathrm{~Hz}, 1 \mathrm{kHz}, 2 \mathrm{kHz}$, and $3 \mathrm{kHz}$. The WRS was measured at the most comfortable hearing level (MCL) using 50 monosyllabic Korean words that are commonly heard during everyday life.

The K-HINT (HINT pro 7.2; Bio-logic ${ }^{\circledR}$ Systems, Natus Medical Inc., CA, USA) was administered with a commercialised instrument in accordance with previously described methods ${ }^{13}$. The test was performed under both quiet and noisy conditions. The reception threshold for speech (RTS), which is the lowest decibel level at which the patient recognised the presented sentence, was measured under quiet conditions. Noisy conditions were divided into three types - front, right, and left noise conditions - and the noise intensity was fixed at $65 \mathrm{~dB}$. The signal-to-noise ratio (SNR) was calculated as the lowest decibel level at which the patient could correctly repeat around $50 \%$ of the presented sentences under noisy conditions with the noise intensity of $65 \mathrm{~dB}$ deducted. The composite SNR, which represented hearing under general noisy conditions, was calculated as follows: $2 \times$ (front noise + right noise + left noise) / 4 . The gain was calculated as the K-HINT data without the AMEI minus the K-HINT data with the AMEI.

\section{Subjective assessment}

The Abbreviated Profile of Hearing Aid Benefit (APHAB) questionnaire is a reliable tool for quantifying the benefits of various hearing-aided conditions. It consists of four subscales: ease of communication (EC), reverberation, background noise $(\mathrm{BN})$, and aversiveness. Each percentage subscale measures adverse reactions to various environmental sounds. For the APHAB, a lower score indicates a greater level of comfort; for the benefit score, a larger score indicates a greater level of satisfaction. The APHAB score for the HA-aided state was measured preoperatively, and the APHAB score for the VSB-aided state was measured at 3 months postoperatively. The scores were analysed and compared as subscales.

\section{Statistical analysis}

An independent $t$-test and a paired $t$-test were used. All statistical analyses were performed with SAS for Windows software (ver. 9.2; SAS Institute Inc., Cary, NC, USA).

\section{Results}

\section{Patient demographics}

The mean patient age was 60.8 years (range: $27-76$ years) and all patients were male. Four patients wore receiverin-the-canal (RIC)-type HAs and two wore in-the-canal (ITC)-type HAs. Among these, three patients wore bilateral HAs; two patients stopped wearing contralateral HAs after implantation, and the other patient wished to achieve better hearing ability and decided to receive a hybrid cochlear implant; this patient is now content with using bimodal HAs. Three patients who wore a single HA received the implantation in the same ear, and the contralateral ear was not treated either before or after implantation. Vibroplasty was performed in the right ear in four cases and in the left ear in two cases. Information regarding the patients is given in Table I.

\section{Objective results}

The preoperative unaided hearing threshold was 51.9 $\pm 7.2 \mathrm{~dB}$. The average PTA with an HA and VSB was $44.0 \pm 11.9 \mathrm{~dB}$ and $40.4 \pm 7.0 \mathrm{~dB}$, respectively (Fig. 1A). With the average PTA value, which was defined as the mean of the $500 \mathrm{~Hz}, 1 \mathrm{kHz}, 2 \mathrm{kHz}$, and $3 \mathrm{kHz}$ frequencies, the difference between the hearing threshold with an HA and that with the VSB was not meaningful. The functional hearing gain (FHG) of each device was then analysed. Again, no significant difference was found between the two devices even though the average FHG was improved with the VSB $(11.5 \pm 3.1 \mathrm{~dB}$ vs. $7.9 \pm 8.5 \mathrm{~dB}, p>0.05)$. We then analysed the average high-frequency hearing gain, which refers to the mean of frequencies greater than or equal to $2 \mathrm{kHz}$ and is critical for hearing rehabilitation in sloping type hearing loss patients. The high-frequency hearing gain with the VSB was $26.0 \pm 3.7 \mathrm{~dB}$, which was significantly better than that with an HA, of $18.1 \pm 18.0$ $\mathrm{dB}(p<0.05$, Fig. 1B).

The WRS was compared for each device. The WRS improved from $55.7 \%$ to $62.3 \%$ with an HA, and from $55.7 \%$ to $66.3 \%$ with the VSB (analysis of variance, $p>$ 0.05 , Fig. 1B). The WRS was measured at the MCL of each patient, and the initial MCLs, with an HA and the VSB, were compared. The initial MCL, of $77.4 \pm 9.5 \mathrm{~dB}$,

Table I. Patient characteristics.

\begin{tabular}{lccccc} 
Patient No. & Sex/age (years) & Implant site & Previous usage of HA & HA type & Contralateral ear treatment after implantation \\
\hline 1 & $\mathrm{M} / 27$ & $\mathrm{~L}$ & Bilateral & RIC & Cl hybrid \\
2 & $\mathrm{M} / 76$ & $\mathrm{R}$ & Unilateral & ITC & No treatment \\
3 & $\mathrm{M} / 65$ & $\mathrm{R}$ & Unilateral & RIC & No treatment \\
4 & $\mathrm{M} / 69$ & $\mathrm{R}$ & Bilateral & RIC & HA refusal \\
5 & $\mathrm{M} / 60$ & $\mathrm{~L}$ & Bilateral & ITC & HA refusal \\
6 & $\mathrm{M} / 68$ & $\mathrm{R}$ & Unilateral & RIC & No treatment \\
\hline
\end{tabular}

$H A$, hearing aid; RIC, receiver-in-the-canal; ITC, in-the-canal; Cl, cochlear implant 


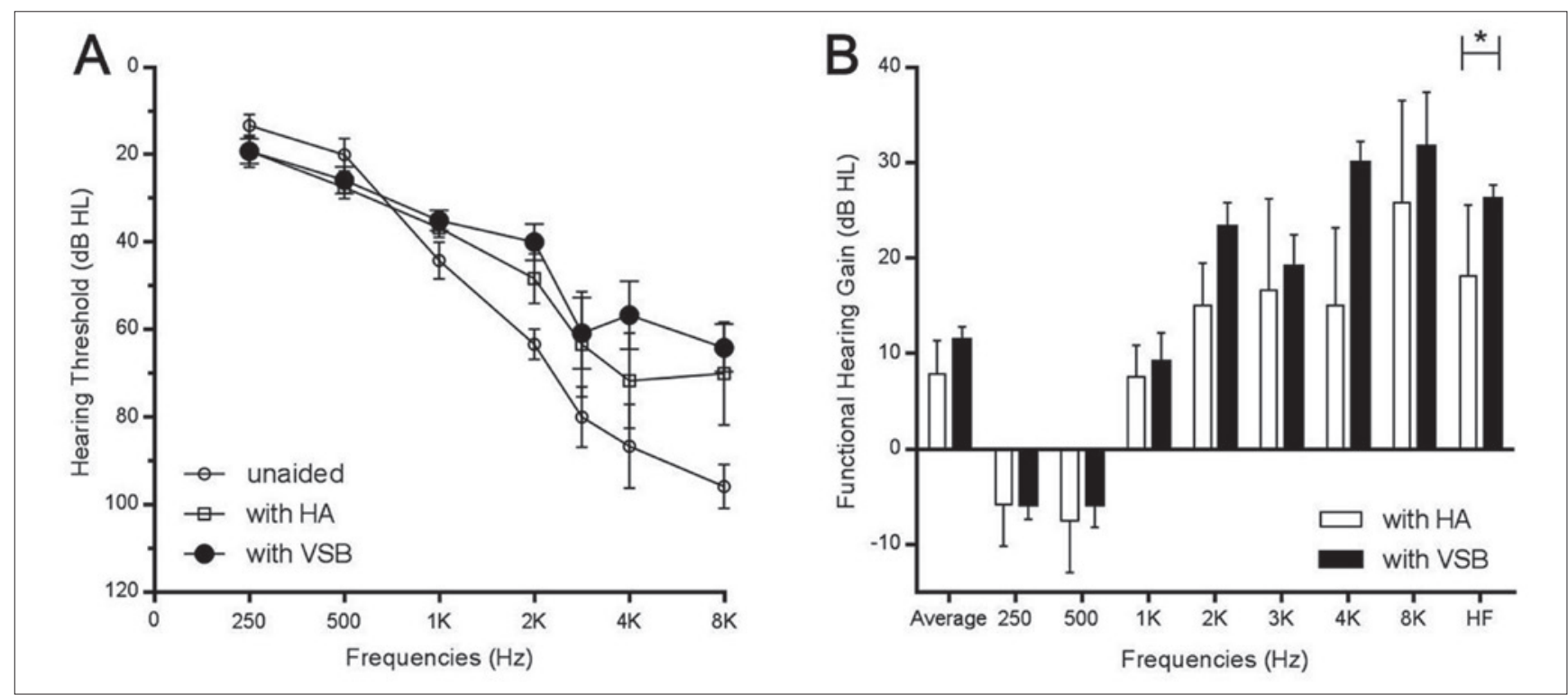

Fig. 1. (A) Summary of the unaided, heading aid (HA)-aided and Vibrant Soundbridge ${ }^{\circledR}$ (VSB)-aided pure-tone thresholds. (B) Functional hearing gain (FHG) as frequencies with HA and VSB. The average FHG did not significantly differ between devices. However, high-frequency hearing gain, which refers to the mean of frequencies $\geq 2 \mathrm{kHz}$, was prominent with the VSB $(26.0 \pm 3.7 \mathrm{~dB}$ vs. $18.1 \pm 18.0 \mathrm{~dB}, p<0.05)$.

Table II. Summary of the K-HINT results according to HA and AMEl usage

\begin{tabular}{llll} 
& Unaided state & With HA & With AMEI \\
Quiet (RTS) & $47.0 \pm 10.5 \mathrm{~dB}$ & $43.2 \pm 6.1 \mathrm{~dB}$ & $35.7 \pm 5.3 \mathrm{~dB}$ \\
Frontal noise & $4.9 \pm 3.7 \mathrm{SNR}$ & $4.4 \pm 2.9 \mathrm{SNR}$ & $2.8 \pm 1.7 \mathrm{SNR}$ \\
Ipsilateral noise & $2.9 \pm 5.3 \mathrm{SNR}$ & $2.3 \pm 2.4 \mathrm{SNR}$ & $-2.0 \pm 3.4 \mathrm{SNR}$ \\
Contralateral noise & $0.6 \pm 2.3 \mathrm{SNR}$ & $2.0 \pm 3.4 \mathrm{SNR}$ & $-4.2 \pm 1.8 \mathrm{SNR}$ \\
Composite & $3.4 \pm 2.9 \mathrm{SNR}$ & $2.3 \pm 1.8 \mathrm{SNR}$ & $-0.3 \pm 1.3 \mathrm{SNR}$ \\
\hline
\end{tabular}

HA, hearing aid; AMEl, active middle ear implant; $R T S$, reception threshold for speech; SNR, signal-to-noise ratio

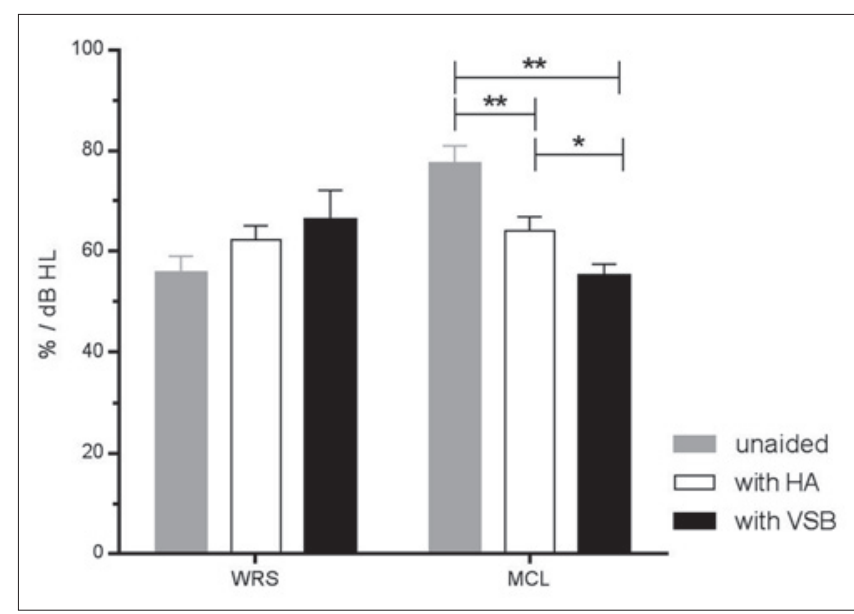

Fig. 2. Improvement in the word recognition score (WRS) and most comfortable level (MCL) at the WRS was measured. Patients benefited most from the VSB, although no significant difference between devices was observed in the comparison of the WRS. The initial MCL decreased from $77.4 \pm 9.5 \mathrm{~dB}$ to $64 \pm 7.4 \mathrm{~dB}$ with an $\mathrm{HA}(p<0.01)$, and to $55.1 \pm 6.1 \mathrm{~dB}$ with the VSB ( $p$ $<0.01)$. The MCL with the VSB was also statistically greater than that with an $\mathrm{HA}(p>0.05) .{ }^{*} p<0.05 ;{ }^{* *} p<0.01$ decreased to $64.0 \pm 7.4 \mathrm{~dB}$ with an $\mathrm{HA}(p<0.01)$ and to $55.1 \pm 6.1 \mathrm{~dB}$ with the VSB $(p<0.01$, Fig. 1B). The MCL with the VSB was also statistically greater than that with an $\mathrm{HA}(p<0.05)$.

The K-HINT scores revealed that patients obtained greater benefits from the VSB under both quiet and noisy conditions. The average RTS for the unaided state was $47.0 \pm$ $10.5 \mathrm{~dB}$, improving to $43.2 \pm 6.1 \mathrm{~dB}$ with an $\mathrm{HA}$ and to $35.7 \pm 5.3 \mathrm{~dB}$ with the VSB. Under the composite noise

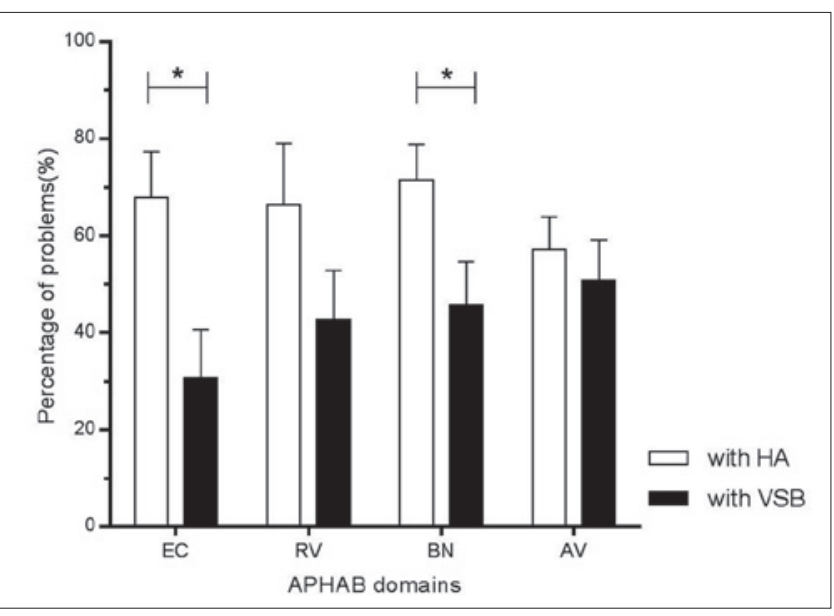

Fig. 3. Comparison of the Abbreviated Profile of Hearing Aid Benefit (APHAB) score with an HA versus the VSB. The APHAB scores were markedly decreased with the VSB. Patients showed greater benefit from the VSB versus the HA on all subscales. EC, ease of communication; RV, reverberation; $\mathrm{BN}$, background noise; $\mathrm{AV}$, aversiveness; ${ }^{*} p<0.05$; ${ }^{* *} p<0.01$ 
condition, the average SNR decreased from $3.4 \pm 2.9 \mathrm{~dB}$ to $2.3 \pm 1.8 \mathrm{~dB}$ with an $\mathrm{HA}$, and from to $-0.3 \pm 1.3 \mathrm{~dB}$ with the VSB (Table II). Even though no statistical significance was observed, patients received the most benefit from the VSB under both quiet and noisy conditions.

\section{Subjective results}

The APAHB scores decreased markedly with the VSB, with particularly significant improvements in EC and $\mathrm{BN}(p<0.05$, Fig. 3). Even though no statistical difference was found, patients were more satisfied with the VSB compared to an HA in all subscales.

\section{Discussion}

This study evaluated the effectiveness of the VSB in patients with sloping high tone hearing loss using both objective and subjective measurements. With the VSB, the average hearing level improved from $51.9 \mathrm{~dB}$ to $40.4 \mathrm{~dB}$, and the improvement was notable at mid-to-high frequencies. Similar results have been obtained by previous studies, either in a sensorineural hearing loss group or a mixed/ conductive hearing loss group. The VSB system is unable to improve hearing at frequencies of 500,250 , and $125 \mathrm{~Hz}$ regardless of whether the FMT is placed on the incus, oval window, or round window ${ }^{14}{ }^{15}$. Needham et al. explained this phenomenon as being a result of the mass loading effect ${ }^{16}$. A loaded mass (stapes, $3 \mathrm{~g}$; FMT, $25 \mathrm{~g}$ ) would result in stiffening of the ossicular ligaments, increasing the tension on the joints, and changing the movement pattern of the ossicular chain ${ }^{17}$. This series of processes leads to limited hearing amplification at low frequencies. Moreover, a study that used vibrometry to assess the operating mechanism of middle ear ossicles reported that the stapes shows rotational movement during high-frequency amplification, which is a more energy-efficient movement than simple lever movement ${ }^{18}$. When high frequencies were amplified with the VSB, physiological rotational movement was apparent rather than simple lever energy transmission movement. These results suggest that the VSB amplifies high frequencies sufficiently and effectively. The characteristics of the VSB provide sufficient functional gain to patients with sloping high tone loss up to $65 \mathrm{~dB}$ without any side effects ${ }^{48}$, whereas HAs limit the range of hearing gain due to occlusion effects.

Previous studies have used the WRS to measure speech gain with the VSB, and some studies have reported that the VSB does not provide additional benefits compared to HAs, because the VSB does not lead to a marked improvement in the WRS relative to HAs ${ }^{11}{ }^{19}$. Similar results were also found in this study. The WRS in the HA- and VSB-aided state hardly differed from each other and it is therefore difficult to demonstrate the benefit of the VSB over HAs. However, in our study the WRS was tested at the MCL, and the level corresponding to the maximum
WRS varies considerably between individuals. Although the WRS is one of the critical factors in verifying speech gain, the MCL should be taken into account when determining patients' comfort indices. In our study, the MCL was significantly better with the VSB compared to the unaided or HA-aided states. This could explain patients' preference for the VSB over an HA, even if the hearing gain is comparable between them.

We also used the K-HINT to evaluate speech gain under noisy conditions. Although there was no statistical difference between the unaided, HA-aided, and VSB-aided states, patients with the VSB showed the most improvements in KHINT scores. They also received the most benefit in contralateral noise conditions. In the K-HINT, a 1-dB change in the SNR generally corresponds to a $9 \%$ change in word intelligibility. Thus, theoretically, patients benefit from a maximum word intelligibility rate of $43.2 \%$ in the unaided state under the application of contralateral noise ${ }^{1320}$.

We anticipated that the VSB would lead to higher subjective satisfaction than the HA. We measured subjective satisfaction quantitatively using the APHAB score. Patients with the VSB showed obvious improvement in the EC and BN subscales of the APHAB compared to their preoperative scores $(p<0.05)$, and achieved better scores over HAs on all subscales. Several factors are likely to affect subjective satisfaction, of which the first is the problem of wearing the device. The VSB, however, solved the problem of feedback and eliminated the occlusion effect. The other problem concerns the ability to achieve a sufficient level of amplification. In patients with sloping high tone loss, in particular, the amplification of high frequencies consequentially incurs unnecessary amplification of low frequencies that can cause an occlusion effect.

Our study demonstrates the efficiency of the VSB over conventional HAs in patients with sloping high tone loss. A conventional HA showed benefits with fitting; however, the VSB was able to provide much better hearing gain at the mid-to-high frequencies that are essential for conversation. The VSB also provided significant benefits under noisy conditions. Overall, a preference for the VSB, and a good level of satisfaction among patients, were observed in our study.

However, as with all retrospective investigations, this study had some limitations. Firstly, patients were fitted with different types of HAs for different durations, such that it was not possible to guarantee that their device had been fitted optimally. Additionally, a 3-month follow-up period was thought to be sufficient to compare the techniques. However, to enable better comparison, a long-term follow-up is needed. Moreover, further studies should include a greater number of subjects to obtain more accurate results. Nevertheless, to our knowledge, this is the first study to compare unaided, HA-aided, and VSB-aided states in the same subjects. 


\section{Conclusions}

The use of vibroplasty in patients with sloping high tone loss resulted in positive hearing outcomes when compared to conventional HAs. Based on the data from this study, the VSB provided both better objective and subjective benefits. The VSB could, therefore, be a better treatment option for sloping hearing loss.

\section{References}

1 Fraysse B, Lavieille JP, Schmerber S, et al. A multicenter study of the Vibrant Soundbridge middle ear implant: early clinical results and experience. Otol Neurotol 2001;22:952-61.

2 Agrawal Y, Platz EA, Niparko JK. Prevalence of hearing loss and differences by demographic characteristics among US adults: data from the National Health and Nutrition Examination Survey, 1999-2004. Arch Intern Med 2008;168:1522-30.

3 Kochkin S. MarkeTrak VIII: The key influencing factors in hearing aid purchase intent. Hear Rev 2012:12-25.

4 Boeheim K, Pok SM, Schloegel M, et al. Active middle ear implant compared with open-fit hearing aid in sloping high-frequency sensorineural hearing loss. Otol Neurotol 2010;31:424-9.

5 Rader T, Fastl H, Baumann U. Speech perception with combined electric-acoustic stimulation and bilateral cochlear implants in a multisource noise field. Ear Hear 2013;34:324-32.

6 Turner C, Gantz BJ, Reiss L. Integration of acoustic and electrical hearing. J Rehabil Res Dev 2008;45:769-78.

7 Luetje CM, Brackman D, Balkany TJ, et al. Phase III clinical trial results with the Vibrant Soundbridge implantable middle ear hearing device: a prospective controlled multicenter study. Otolaryngol Head Neck Surg 2002;126:97-107.

8 Todt I, Seidl RO, Gross M, et al. Comparison of different vibrant soundbridge audioprocessors with conventional hearing AIDS. Otol Neurotol 2002;23:669-73.

9 Uziel A, Mondain M, Hagen P, et al. Rehabilitation for highfrequency sensorineural hearing impairment in adults with the symphonix vibrant soundbridge: a comparative study. Otol Neurotol 2003;24:775-83.

10 Truy E, Philibert B, Vesson JF, et al. Vibrant soundbridge versus conventional hearing aid in sensorineural highfrequency hearing loss: a prospective study. Otol Neurotol 2008;29:684-7.

11 Mosnier I, Sterkers O, Bouccara D, et al. Benefit of the Vibrant Soundbridge device in patients implanted for 5 to 8 years. Ear Hear 2008;29:281-4.

12 Sziklai I, Szilvassy J. Functional gain and speech understanding obtained by Vibrant Soundbridge or by open-fit hearing aid. Acta Otolaryngologica 2011;131:428-33.

13 Moon SK, Mun HA, Jung HK, et al. Development of sentences for Korean Hearing in Noise Test (KHINT). Korean J Otolaryngol 2005:724-8.

14 Hough JV, Matthews P, Wood MW, et al. Middle ear electromagnetic semi-implantable hearing device: results of the phase II SOUNDTEC direct system clinical trial. Otol Neurotol 2002;23:895-903.

15 Sterkers O, Boucarra D, Labassi S, et al. A middle ear implant, the Symphonix Vibrant Soundbridge: retrospective study of the first 125 patients implanted in France. Otol Neurotol 2003;24:427-36.

16 Needham AJ, Jiang D, Bibas A, et al. The effects of mass loading the ossicles with a floating mass transducer on middle ear transfer function. Otol Neurotol 2005;26:218-24.

17 Lee JM, Jung J, Moon IS, et al. Benefits of active middle ear implants in mixed hearing loss: Stapes versus round window. Laryngoscope 2016 doi: 10.1002/lary.26244. [Epub ahead of print]

18 Ball GR, Huber A, Goode RL. Scanning laser Doppler vibrometry of the middle ear ossicles. Ear Nose Throat J 1997;76:213-8, 20, 22.

19 Schmuziger N, Schimmann F, Wengen D, et al. Long-term assessment after implantation of the Vibrant Soundbridge device. Otol Neurotol 2006;27:183-8.

20 Nilsson M, Soli SD, Sullivan JA. Development of the Hearing in Noise Test for the measurement of speech reception thresholds in quiet and in noise. J Acoust Soc Am 1994;95:1085-99. 